\title{
Hubungan Safety Leadership dengan Safety Performance Pada Pekerja Industri Pakan Ternak Sidoarjo
}

\author{
Agustina Agustina, Bachtiar Chahyadhi, Denny Ardyanto \\ Fakultas Kesehatan Masyarakat Universitas Airlangga Surabaya \\ Email:justhyna99@gmail.com
}

\begin{abstract}
The direct cause of accidents often involves human error, organizational factors and management are involved in incidents in all industries. An old paradigm of domino theory which emphasizes that accidents always stem from management mistakes start slowly changed. Human factors such as behavior, motivation, psychology began to be considered. False a behavioral approach to implement a safety culture with safety leadership.This study aims to analyze the relationship between safety leadership factors with safety performance in animal feed industry workers in Sidoarjo. This research is a quantitative study with a cross-sectional approach. The method used to measure the safety leadership factor with safety performance is by filling out questionnaires. The population in this study were 150 people and samples were obtained using the techniquesimple random sampling of 108 workers. The results showed that there wasa correlation between the role of safety leadership of supervisors and safety performance of 0.023.Suggestions that can be applied to improve safety performance with add jobdesk safety leadership to supervisors to motivate and direct workers to participate in company safety programs and by promoting workers who have a leadership style of achievement orientation become a supervisor.
\end{abstract}

Keywords: Safety leadership, Safety performance, Animal feed industry

\begin{abstract}
ABSTRAK
Penyebab langsung kecelakaan sering melibatkan kesalahan manusia, faktor organisasi dan manajemen terlibat dalam insiden di semua industri. Paradigma lama dari teori domino yang menekankan bahwa kecelakaan selalu berakar dari kesalahan manajemen mulai perlahan dirubah. Faktor-faktor manusia seperti perilaku, motivasi, psikologi mulai
\end{abstract}


diperhatikan. Salah satu pendekatan perilaku untuk menerapkan budaya keselamatan dengan safety leadership. Penelitian ini bertujuan untuk menganalisis hubungan faktor safety leadership dengan safety performance pada pekerja industri pakan ternak di Sidoarjo. Penelitian ini merupakan suatu penelitian kuantitatif dengan pendekatan cross sectional. Metode yang digunakan untuk mengukur faktor safety leadership dengan safety performance yaitu pengisian kuesioner. Populasi dalam penelitian ini ada 150 orang dan sampel yang diperoleh menggunakan teknik simple random sampling sebanyak 108 pekerja. Hasil penelitian menunjukkan bahwa ada hubungan peranan safety leadership dari supervisor dengan safety performance sebesar 0,023. Saran yang bisa diterapkan untuk meningkatkan safety performance dengan menambahkan jobdesk safety leadership kepada supervisor agar memotivasi dan mengarahkan pekerja untuk berpartisipasi dalam program keselamatan perusahaan. Mempromosikan pekerja yang mempunyai karakter gaya kepemimpinan orientasi prestasi menjadi supervisor.

Kata kunci: Kepemimpinan Keselamatan, Kinerja Keselamatan, Industri Pakan Ternak

Kinerja keselamatan kerja merupakan salah satu keberhasilan suatu perusahaan dalam menerapkan sistem manajemen keselamatan dan kesehatan kerja. kinerja keselamatan yang baik menunjukkan bahwa perusahaan berkomitmen untuk mencegah kecelakaan dan penyakit akibat kerja serta meningkatkan produktivitas kerja. Rendahnya penerapan sistem manajemen keselamatan dan kesehatan kerja merupakan salah satu faktor penyebab kecelakaan kerja, laporan kecelakaan kerja berdasarkan International Labour Oganization (2017), setiap 15 detik terdapat 153 pekerja yang mengalami kecelakaan kerja atau 317 juta kecelakaan setiap tahunnya yang mengakibatkan 6300 pekerja meninggal dunia, meningkatkan angka absensi, hilangnya jam kerja dan pengeluaran biaya sebesar 4\% dari Gross Domestic Product setiap tahunnya.

Penyebab kecelakaan kerja tersebut baik dari faktor manusia maupun faktor pekerjaan harus segera dilakukan pencegahan untuk menjamin lingkungan kerja yang aman dan pekerja bekerja dengan selamat. Peranan pemimpin juga mampu meminimalkan terjadinya kecelakaan serta meningkatkan kinerja keselamatan baik secara personal maupun perusahaan. Peranan pemimpin yang bisa menjadi contoh atau role models, memotivasi, dan mendorong para bawahannya berperilaku aman dalam bekerja menjadi kunci suksesnya perusahaan dalam meningkatkan kinerja keselamatan. 
Industri Pakan Ternak Sidoarjo merupakan perusahaan yang menjalankan kegiatan usaha adalah memproduksi pakan ternak, berdasarkan hasil observasi potensi bahaya debu organik, debu bahan addictive, iklim kerja, bising, bahaya sikap kerja yang tidak alamiah, lalu lalang kendaraan forklift, ditemukan pekerja yang bekerja tidak aman seperti bekerja diketinggian tanpa pengaman, bekerja tanpa alat pelindung diri, belum memahami terhadap bahaya di tempat kerja dan hasil audit internal SMK3 berdasarkan PP 50 Tahun 2012 64 kriteria tahap awal mendapatkan hasil 71\% artinya penerapan SMK3 sudah berjalan namun masih terdapat beberapa temuan audit, maka dibutuhkan kepemimpinan yang mampu merubah perilaku pekerja tidak aman menjadi pekerja yang berbudaya keselamatan kerja serta mampu meningkatkan kinerja keselamatan personal dan perusahaan.

$\mathrm{Wu}$ (2008) mendefinisikan safety leadership sebagai proses interaksi antara pimpinan dan pekerja, dimana pimpinan dapat mempengaruhi pekerja untuk mencapai tujuan keselamatan kerja organisasi dengan kondisi yang ada pada organisasi dan diri pekerja. Safety leadership diukur melalui tiga dimensi yaitu kepedulian terhadap keselamatan kerja (safety caring), pembinaan terhadap keselamatan kerja (safety coaching), dan pengontrolan terhadap keselamatan kerja (safety controlling).

Clarke (2013) menjelaskan bahwa safety leadership itu merupakan interaksi sosial dengan bawahan, dimana ada rasa saling percaya yang tumbuh, pertukaran perhatian para pemimpin untuk keselamatan dan kesehatan kerja. Proses interaksi tersebut akan mendorong pemimpin untuk memperhatikan aspek keselamatan dan kesehatan kerja. Kepemimpinan keselamatan dapat didefinisikan sebagai proses interaksi antara pemimpin dan pengikut, di mana para pemimpin dapat menggunakan pengaruhnya pada pengikut untuk mencapai tujuan keselamatan organisasi di bawah keadaan faktor organisasi dan individu (Wu, 2005).

Penerapan safety leadership sebagai salah satu upaya membudayakan keselamatan di tempat kerja dibutuhkan komitmen dan kerjasama dari seluruh elemen perusahaan baik dari jajaran top manajer sampai ke level pekerja (Suma,mur, 2009). Fendi (2017), menjelaskan salah satu faktor terlaksananya penerapan keselamatan dan kesehatan kerja dengan safety leadership melalui pendekatan motivasi dan arahan dari pimpinan kepada pekerja sehingga meningkatkan kinerja keselamatan individu dan perusahaan.

Safety leadership akan mampu meningkatkan kinerja SMK3 di dalam perusahaan melalui empat elemen yaitu, pemimpin harus mempunyai visi misi dan komitmen untuk membangun keselamatan dan kesehatan kerja, pemimpin harus fokus membudayakan perilaku keselamatan, pemimpin harus mempunyai program untuk mewujudkan budaya 
keselamatan dan pemimpin harus memberikan pengaruh keselamatan agar aktivitas pekerjaan dilakukan dengan aman (Blair, 2003).

Walliams, (2002) mengatakan untuk membentuk safety leadership diperlukan pemimpin yang mampu memanfaatkan kepemimpinannya dengan membuat komitmen keselamatan, dan mendorong budaya keselamatan, Cooper (1998) mengatakan bahwa pemimpin yang efektif adalah pemimpin yang proaktif, peduli dan selalu mengontrol atau mengevaluasi organisasinya, dengan memanfaatkan komunikasi untuk menyediakan sumber daya yang diperlukan, dan menghilangkan hambatan organisasi. Natalie, Charles (2015) menunjukkan adanya pengaruh safety leadership dan behavior leadership terhadap safety culture dan safety performance pada industri konstruksi. Peningkatan safety performance dilihat dari sistem manajemen keselamatan dan kesehatan kerja yang berlandaskan kepemimpinan, komunikasi, komitmen $\mathrm{K} 3$ dan pelatihan pekerja.

Peranan safety leadership untuk membangun keselamatan dan kesehatan kerja begitu penting. Komitmen dan keterlibatan pemimpin tidak dengan setulus hati dalam berinteraksi dengan pekerja maka akan sulit untuk dilakukan penerapan keselamatan kerja. Menurut $\mathrm{Wu}$, Chen, dan Li (2008) pengawasan keselamatan dalam safety leadership memberikan pengaruh komitmen dan tindakan keselamatan bagi pemimpin perusahaan dan para manager. Sikap dan perilaku tenaga kerja akan ditentukan oleh sikap dan perilaku pemimpinnya di tempat kerja. Memahami dan menyakini pentingnya keselamatan kerja bagi bisnis perusahaan merupakan langkah awal yang dilakukan pemimpin, Gunawan (2013).

Occupational Safety Health Administration (OSHA) (1996), upaya untuk mengurangi kesalahan atau insiden manusia adalah penerapan safety leadership, kekuatan kepemimpinan dan menunjuk kepemimpinan manajemen sebagai elemen kunci dalam masalah penerapan keselamatan dan kesehatan kerja. Pemimpin harus memotivasi team anggota untuk bekerja lebih keras, bekerja secara efisien, dan tanggung jawab untuk meningkatkan kinerja keselamatan (O`Dea dan Flin, 2001).

Health and Safety Excecutive / HSE (2014) menyatakan bahwa tanpa kepemimpinan yang efektif, seseorang tidak dapat memiliki kemampuan untuk meningkatkan kinerja keselamatan. The Federal Safety Commissioner (2006) juga menekankan pentingnya kepemimpinan keselamatan dari para manajer senior dalam mencapai budaya keselamatan, sehingga menghasilkan peningkatan kinerja keselamatan organisasi, dan mengurangi kecelakaan kerja. Perilaku kepemimpinan dalam menerapkan sistem manajemen keselmatan dan kesehatan kerja, menurut Gunawan (2013) contoh tindakan yang 
harus dilakukan pemimpin yaitu:

1. Menunjukkan komitmennya dalam keselamatan dan kesehatan kerja

2. Menjadi contoh perilaku

3. Memastikan penerapan sistem manajemen keselamatan dan kesehatan kerja berjalan

4. Menjadikan keselamatan dan kesehatan kerja yang selalu diutamakan

5. Memantau kinerja SMK3 baik lagging atau leading indikator

6. Memberikan dukungan untuk dilakukan perbaikan secara berkelanjutan.

Faktor yang menentukan peranan safety leadership dengan pendekatan safety motivation, safety policy, dan safety concern akan mampu meningkatkan penerapan kinerja sistem manajemen keselamatan dan kesehatan kerja (Lu, C \& Yang, 2010).

Griffin dan Neal (2000) melihat kinerja keselamatan sebagai aspek kinerja kerja dan mengusulkan model kinerja keselamatan berdasarkan teori kinerja pekerjaan (Borman dan Motowidlo, 1993; Campbell et al., 1993). Mereka mengidentifikasi dua komponen kinerja keselamatan: kepatuhan keselamatan dan partisipasi keselamatan. Kepatuhan keselamatan mengacu pada kegiatan keselamatan inti yang harus dilakukan karyawan untuk menjaga keselamatan di tempat kerja, seperti mengikuti peraturan dan prosedur keselamatan dan menggunakan alat pelindung diri (APD) dengan benar (Griffin dan Neal, 2000). Pemenuhan keselamatan mencakup perilaku karyawan yang meningkatkan kesehatan dan keselamatan pribadi mereka sendiri dan itu dapat dianggap sebagai bagian dari peran kerja karyawan. Partisipasi keselamatan, di sisi lain, mengacu pada perilaku yang tidak secara langsung meningkatkan keselamatan di tempat kerja tetapi membantu menciptakan suasana yang mendukung keselamatan, seperti partisipasi sukarela dalam kegiatan keselamatan atau kehadiran di pertemuan keselamatan (Griffin dan Neal, 2000). Partisipasi keselamatan mencakup perilaku yang mendukung tujuan dan sasaran organisasi di bidang ini (Vinodkumar dan Bhasi, 2010), dan oleh karena itu, melibatkan elemen sukarela yang lebih besar daripada kepatuhan keselamatan, termasuk perilaku yang melampaui peran formal karyawan, dengan kata lain perilaku kewargaan organisasional (Clarke, 2006).

Contextual performance dapat dipahami sebagai upaya yang dilakukan oleh individu yang tidak berhubungan langsung dengan pekerjaan utamanya namun penting dalam membentuk organisasi, lingkungan social dan psikologis karyawan sebagaimana fungsi perusahaan dilakukan (Neal, 2000 dalam Muniz, 2017). Berikut ini merupakan penjelasan 
mengenai dimensi safety performance:

a. Safety Compliance

Safety compliance mengacu pada komponen task performance yang digunakan untuk mendeskripsikan aktivitas keselamatan inti yang digunakan oleh individu untuk menjaga keselamatan di lingkungan kerja. Perilaku pada safety compliance meliputi kepatuhan pada peraturan keselamatan yang ada, penggunaan alat pelindung diri (APD) dan bagaimana individu berperilaku secara aman pada saat bekerja (Neal, 2000).

b. Safety Participation

Safety participation mengacu pada contextual performance yang digunakan untuk mendeskripsikan perilaku-perilaku yang berhubungan dengan partisipasi pada keselamatan kerja seperti menghadiri rapat terkait keamanan \& keselamatan kerja, mengingatkan sesama rekan kerja untuk selalu berperilaku aman dan bergabung pada aktivitas keamanan (Neal., dkk. 2000).

\section{METODE}

Penelitian ini dilakukan pada bulan Januari 2019 di Industri Pakan Ternak Sidoarjo, penelitian ini adalah jenis penelitian observatioanl dengan pendekatan cross sectional. Populasi dalam penelitian ini adalah 150 pekerja kemudian diambil sampel sejumlah 108 pekerja dengan

random sampling sesuai ukuran departemen. Variabel independen dalam penelitian ini adalah motivasi kerja dengan pendekatan prestasi, pertumbuhan, pengakuan, tanggung jawab dan pekerjaan itu sendiri. Variabel dependen adalah safety performance dengan pendekatan safety compliance dan safety participation.

Data yang diperoleh akan disajikan secara deskriptif terhadap tiap variabel dari hasil penelitian, sehingga dapat memberi gambaran motivasi kerja dan safety performance. Analisis variabel untuk mengetahui apakah ada atau tidak hubungan antar variabel penelitian. Analisis bivariat menggunakan uji Chi Square dengan bantuan program SPSS versi 17 (Sopiyudin, 2011).

\section{HASIL}

\section{Safety Leadership}

Pengukuran safety leadership didasarkan pada pendekatan safety motivation dan safety concern. Peran supervisor dalam memotivasi dan fokus terhadap sangat diperlukan dalam meningkatkan K3 diperusahaan. Faktor safety leadership dinilai oleh responden disesuaikan 
dengan unit kerjanya. Berdasarkan responden pada penelitian ini didapatkan distribusi sebagai berikut:

Tabel 1. Distribusi Faktor Safety Leadership

\begin{tabular}{lll}
\hline \multirow{2}{*}{ Variabel } & \multicolumn{2}{c}{ Safety Leadership } \\
\cline { 2 - 3 } & $\mathrm{n}$ & $\%$ \\
\hline Rendah & 52 & 48.1 \\
Tinggi & 56 & 51.9 \\
Total & 108 & 100 \\
\hline
\end{tabular}

Peranan supervisor dalam aspek keselamatan kerja adalah memberikan mendorong, dan memotivasi, pekerja untuk berperilaku aman dalam bekerja, koordinasi untuk memecahkan masalah dalam keselamatan dan kesehatan sebesar, serta melakukan pengawasan pekerjaan baik aspek keselamatan, mutu, dan produktivitas.

\section{Safety Performance}

Safety Performance diukur menggunakan kuesioner dengan pendekatan kepatuhan dan partisipasi dari responden tentang keselamatan kerja. Tabel 2 menjelaskan bahwa safety performance seluruh responden dari hasil kuisioner Didapatkan hasil kinerja keselamatan atau safety performance pada kategori tinggi sebesar 56,5\%.

Table 2. Distribusi Frekuensi Safety Performance

\begin{tabular}{|l|c|c|}
\hline \multirow{2}{*}{ Kategori } & \multicolumn{2}{|c|}{ Variabel } \\
\cline { 2 - 3 } & \multicolumn{2}{|c|}{ Safety Performance } \\
\cline { 2 - 3 } & $\mathrm{n}$ & $\%$ \\
\hline Rendah & 47 & 43.5 \\
\hline Tinggi & 61 & 56.5 \\
\hline Total & 108 & 100 \\
\hline
\end{tabular}

\section{Hubungan Safety Leadership dengan Safety Performance}

Tabel 3 menunjukkan bahwa ada hubungan antara faktor safety leadership dengan safety performance yang signifikan dibuktikan dengan uji X2 0,023 dengan prevalence ratio (PR) 1,735 artinya safety leadership dari supervisor mampu meningkatkan safety performance responden. Hasil analisis statistik menunjukan nilai $p$ value $=0,023$ itu berarti $(p>0,05)$ yang diperoleh dari Chi Square Test, dengan prevalence ratio (PR) 1,735 menunjukkan bahwa ada hubungan yang signifikan antara faktor safety leadership dengan safety performance pada pekerja di Industri Pakan Ternak Sidoarjo. 
Tabel 3 Hubungan Faktor Safety Leadership dengan Safety Performance

\begin{tabular}{|l|c|c|c|c|}
\hline \multirow{2}{*}{ Laktor Safety } & \multicolumn{4}{|c|}{ Safety Performance } \\
\cline { 2 - 5 } & \multicolumn{2}{|c|}{ Rendah } & \multicolumn{2}{c|}{ Tinggi } \\
\cline { 2 - 5 } & $\mathrm{n}$ & $\%$ & $\mathrm{n}$ & $\%$ \\
\hline Rendah & 29 & 61.7 & 23 & 37,8 \\
\hline Tinggi & 18 & 38.3 & 38 & 62,2 \\
\hline Total & 47 & 100 & 61 & 100 \\
\hline Uji statistik & \multicolumn{2}{|c|}{$\mathrm{X} 2$} & \multicolumn{2}{c|}{ PR } \\
\cline { 2 - 5 } & \multicolumn{2}{|c|}{0,023} & \multicolumn{2}{c|}{1,735} \\
\hline
\end{tabular}

\section{PEMBAHASAN}

\section{Safety Leadership}

Faktor safety leadership merupakan bentuk motivasi, dorongan, dan koordinasi untuk memecahkan masalah keselamatan dan kesehatan dari atasan atau supervisor setiap unit kerja kepada pekerja. Pengukuran faktor safety leadership bertujuan untuk mengukur sejauh mana peran supervisor dalam setiap unit kerja memberikan pengaruh keselamatan dan kesehatan kerja.

Peranan supervisor dalam aspek keselamatan kerja adalah memberikan mendorong, dan memotivasi, pekerja untuk berperilaku aman dalam bekerja, koordinasi untuk memecahkan masalah dalam keselamatan dan kesehatan sebesar, serta melakukan pengawasan pekerjaan baik aspek keselamatan, mutu, dan produktivitas.

\section{Safety Performance}

Kepatuhan atau safety compliance dalam keselamatan kerja mempunyai peran yang penting, karena safety compliance mampu meminimalkan terjadinya kecelakaan kerja. Partisipasi dalam keselamatan kerja dibutuhkan untuk mendukung semua program keselamatan, dan meningkatkan pengetahuan dan ketrampilan pekerja.

Pekerja di Industri Pakan Ternak Sidoarjo memiliki kepatuhan yang tinggi terhadap peraturan keselamatan kerja yang ditetapkan, dan partisipatif dengan program keselamatan kerja. Pedoman kinerja keselamatan didasarkan pada job desk pada level pekerja, supervisor atau manager. 


\section{Analisis Hubungan Safety Leadership dengan Safety Performance}

Skeepers \& Mbohwa (2015) menyatakan bahwa suatu organisasi yang berhasil mengelola safety performance karyawan cenderung memiliki pemimpin yang dapat mempengaruhi secara efektif perilaku karyawan melalui perilaku kepemimpinan yang diterapkan.

Supervisor disetiap unit Industri Pakan Ternak Sidoarjo diperlukan untuk meningkatkan kinerja keselamatan pekerja, sebagai pengawas pekerjaan, supervisor juga dituntut untuk memahami setiap bahaya ditempat kerja, memikirkan aspek keselamatan kerja bagi pekerjanya, untuk itu diperlukan supervisor yang mampu memotivasi dan fokus terkait keselamatan kerja, selain itu memberikan apresiasi kepada pekerja, mengingatkan pekerja yang tidak menggunakan alat pelindung diri pada saat bekerja, membuat manajemen risiko pekerjaan, serta meminta kelengkapan alat pelindung diri. Program inspeksi harus selalu dilakukan untuk mengukur dan mengevaluasi penerpan keselamatan di unit kerja serta memberikan masukan dari temuan yang belum sesuai dengan peraturan atau program yang ditetapkan perusahaan.

Penelitian lain menjelaskan bahwa safety leadership memiliki pengaruh langsung yang signifikan dan positif terhadap safety performance karyawan. Hal ini sejalan dengan penelitian oleh Fernandez-Muniz, (2014) dan Kapp, (2012) menunjukkan bahwa safety leadership dapat memberikan contoh perilaku terhadap karyawan untuk bekerja lebih keras, lebih efisien dan mengambil tanggung jawab untuk meningkatkan safety performance. Adanya contoh perilaku, arahan dan motivasi dari pemimpin yang mengutamakan keselamatan kerja akan diikuti oleh bawahan untuk menampilkan safety performance saat melakukan pekerjaan.

Lu \& Yang (2008) menjelaskan pemimpin yang mengutamakan keselamatan kerja akan menetapkan perilaku standar dan memotivasi karyawan serta menekankan kesadaran akan pentingnya peralatan dan peraturan keselamatan kerja. Cara tersebut akan membuat karyawan akan secara bertahap mengubah perilakunya atas instruksi dan memperoleh informasi bagaimana cara bekerja dengan aman sehingga sadar akan pentingnya menampilkan safety performance saat melakukan pekerjaan.

Zuofa dan Edward, (2017) berkontribusi dengan memperkenalkan konsep safety leadership dalam bidang keselamatan di tempat kerja. Safety leadership membutuhkan komitmen pemimpin untuk aktif dalam penerapan keselamatan kerja dan kesejahteraan karyawan memiliki pemimpin yang memperhatikan faktor keselamatan, maka para karyawan 
cenderung merasa faktor keselamatan sangat diutamakan. Peran pemimpin dalam keselamatan menurut Gunawan, (2013) adalah pemimpin itu mampu menjadi contoh perilaku, bahwa keselamatan kerja sangat penting menjadi role models yang baik meliputi:

1. Pemimpin yang mematuhi dan menerapkan aturan keselamatan yang konsisten dan tanpa pengecualian dimulai dari dirinya sendiri. Tindakan ini penting untuk memberikan pandangan kepada seluruh anggota organisasi bahwa pemimpin melaksanakan apa yang diucapkan.

2. Mengkomunikasikan pentingnya keselamatan dalam bekerja, ikut serta dalam safety talk, dan safety induction.

3. Terlibat dalam kegiatan keselamatan kerja, meliputi inspeksi keselamatan, dan memonitoring program keselamatan.

4. Mendorong, memotivasi, dan memberikan semangat kepada pekerja untuk berkontribusi dalam pelaksanaan keselamatan kerja, tujuan dapat dicapai dengan memberikan penghargaan, dan memberikan pengakuan kepada pekerja yang memiliki kinerja keselematan yang baik.

5. Menetapkan keselamatan kerja dalam key performance indicator perusahaan.

\section{SIMPULAN}

Terdapat hubungan antara faktor safety leadership dengan safety performance, supervisor yang memperhatikan keselamatan di tempat kerja akan berperilaku untuk mendorong dan memotivasi pekerjanya bekerja dengan aman, menyediakan perlengkapan keselamatan, dan tanggap mengenai masalah keselamatan sehingga membuat bawahannya akan mencontoh perilaku dari supervisornya, sehingga partisipasi dan kepatuhan bawahannya terkait keselamatan kerja akan meningkat.

1. Memasukkan aspek safety leadership sebagai tugas dan tanggung jawab supervisor untuk meningkatkan kinerja keselamatan perusahaan.

2. Menerapkan program STOP yaitu menghentikan pekerjaan yang tidak aman, mengkomunikasikan bahaya dan pengendaliaannya serta memberikan penghargaan atau pujian kepada pekerja yang berperilaku aman. 


\section{DAFTAR RUJUKAN}

Atmojo A., Purnomo I., dan Muljono S. (2018). The Influence of Organizational Culture on Inpatient Staff Performance of QIMHospital. Unnes Journal of Public Health 7 (1)(2018).

Clarke S, (2006). The relationship between safety climate and safety performance: A metaanalytic review. Journal of Occupational Health Psychology 11, 315-327.

Clarke S, (2013). Safety leadership: A meta-analytic review of transformational and transactional leadership styles as antecedents of safety behaviors. Journal of Occupational and Organizational Psychology, 86, 22-49.

Cooper M.D, (1998). Improving Safety Culture: A Practical Guide. Wiley, England.

Fendi K, (2017). Pengaruh safety leadership dan safety climate terhadap safety performance karyawan dengan safety knowledge, Tesis. Program Magister Universitas Airlangga. Program Studi Psikologi Profesi.

Griffin M.A dan Neal A, (2000). Perceptions of safety at work: A framework for linking safety climate to safety performance, knowledge, and motivation. Journal of Occupational Health Psychology 5, 347-358.

Gunawan, (2013). Safety Leadership Kepemimpinan Keselamatan Kerja (Building Excellent Operation). Jakarta: Dian Rakyat

Government Regulation of Indonesian Nomor. 50/MEN/2012 about Occupational Safety and Health Management System.

HSE, (2014). Occupational Health and Safety Annual Report in Great Britain. (Sitasi 15 Oktober 2018)

International Labour Organization/Encyclopedia of Occupational Health and Safety Edisi tahun ke-4/ http://www.ilocis.org/documents/chpt56e.htm (sitasi pada 3 November 2018)

Kapp, E. (2012). The Influence of Supervisor Leadership Practices and Perceived Group Safety Climate on Employee Safety Performance. Safety Science 50 (2012) 1119-1124.

Lu C dan Yang C, (2010). Safety leadership and safety behavior in container terminal operations. Journal of Safety Science, 48, 123-134.

Natalie \& Charles, (2015). A Study On The Leadership Behaviour, Safety Leadership And Safety Performance In The Construction Industry In South Africa. Proceeding of Industrial Engineering and Service Science. 
O'Dea A dan Flin R, (2001). Site managers and safety leadership in the offshore oil and gas industry. Safety Science 37, 39-57.

Sopiyudin, (2014). Statistik Untuk Kedokteran dan Kesehatan. Jakarta: Salemba Medika. pp 197

Suma'mur, (2009). Higene Perusahaan dan Kesehatan Kerja. Jakarta: CV. Sagung Seto (Edisi I)

Vinodkumar M.N dan Bhasi M, (2010). Safety management practices and safety behaviour: Assessing the mediating role of safety knowledge and motivation. Accident Analysis and Prevention 42, 2082-2093.

Wu T, Chen C, \& Li C, (2008). A correlation among safety leadership, safety climate, and safety performance. Journal of Loss Prevention in the Process Industries, 21, 307-318.

Zuofa \& Edward, (2017). Senior managers and safety leadership role in offshore oil and gas construction projects. Creative Construction Conference 2017, CCC 2017, 19-22 June 2017, Primosten, Croatia. 